Divya Bhardwaj FFARCSI, Andrew Norris FRCA, David T. Wong MD

\title{
Is skin puncture benefi- cial prior to arterial catheter insertion?
}

Purpose: To compare the insertion time and incidence of catheter damage between skin puncture (SP) and no skin puncture (NP) techniques prior to arterial catheter insertion in patients undergoing neurosurgery.

Methods: Patients undergoing surgery for intracranial tumours or cervical spine lesions were randomized to receive either SP or NP prior to arterial catheter insertion. The total insertion time, number of passes made, number of catheters used, method of insertion (direct or transfixation) and whether catheter was inserted with patients awake or anesthetised were recorded. After removal, catheters were examined microscopically for damage.

Results: Eighty-two patients, 36 in SP group and 46 in NP group were recruited. Microscopic damage was seen in $36.5 \%$ of catheters and there was no difference between the two groups. The mean/median insertion time were $180 / 62 \mathrm{sec}$ and $205 / 77 \mathrm{sec}$ for SP and NP respectively (P:NS). The insertion time was shorter for the direct than for the transfixation technique with median of $42 \mathrm{vs} 174 \mathrm{sec}(P=0.00 \mathrm{I})$.

Conclusion: There are no differences in insertion time or catheter damage between skin puncture and no skin puncture techniques prior to arterial catheter insertion. The practice of skin puncture may be abandoned resulting in decreased risk of needlestick injury.

Objectif : Comparer, chez des patients de neurochirurgie, le temps d'insertion d'un cathéter et l'incidence d'un dommage lorsque l'insertion artérielle se fait avec une incision cutanée (IC) préalable ou sans incision (SI).

Méthode : Des patients, en chirurgie pour une tumeur intracrânienne ou une lésion de la colonne cervicale, ont été répartis de façon aléatoire en groupes IC ou SI pour l'insertion d'un cathéter artériel. On a noté : le temps total d'insertion, le nombre d'essais réalisés, le nombre de cathéters utilisés, la méthode d'insertion (directe ou indirecte) et l'état du patient à ce moment (éveillé ou endormi). Les cathéters retirés, on les a examinés sous microscope pour évaluer les dommages.

Résultats : Quatre-vingt-deux patients, 36 dans le groupe IC et 46 dans le groupe SI ont été recrutés. Des dommages ont été vus au microscope sur $36,5 \%$ des cathéters, sans différence entre les groupes. Le temps d'insertion moyen/médian était de $180 / 62$ s et de $205 / 77$ s pour les groupes IC et SI respectivement ( $P$ : NS). Le temps d'insertion était plus court selon la technique directe par rapport à la technique indirecte et la médiane était de 42 vs $174 \mathrm{~s}(P=0,001)$.

Conclusion : II n'y a pas de différence de temps d'insertion ou de dommage au cathéter entre les techniques utilisant ou non l'incision cutanée préalable à l'introduction dans l'artère. L'incision cutanée peut être abandonnée, ce qui diminue les risques de lésion au point de ponction.

From the Department of Anaesthesiology, The Toronto Hospital and Mount Sinai Hospital, University of Toronto, 399 Bathurst Street, Toronto, Ontario, M5T 288 .

Address correspondence to: Dr. DT. Wong MD, Department of Anaesthesiology, Toronto Hospital, Western Division, 399 Bathurst

Street, Toronto, Ontario M5T 2S8. Phone: 416-603-5118; Fax: 416-603-6494; E-mail: dwong@torhosp.toronto.on.ca. Accepted for publication November 7,1998 
A RTERIAL catheters are commonly used in major surgery for direct arterial pressure monitoring and to enable repeated blood gas sampling. Various techniques of insertion are described to facilitate the placement of these catheters in peripheral arteries. ${ }^{1}$ It has been shown that considerable damage to arterial walls can occur with multiple attempts at cannulation. ${ }^{2}$ If the catheter is damaged during insertion it increases the likelihood of arterial wall injury. ${ }^{3}$ Therefore, techniques were developed to make the insertion of these catheters as easy and as atraumatic as possible. One such recommendation has been to make a skin puncture with a large bore needle prior to insertion of the catheter. ${ }^{4-9}$ It is said to reduce the likelihood of catheter damage and to make catheter insertion easier., $, 5,8,9$ However this assumption has not been established. Despite the lack of evidence to support it, skin puncture is widely performed prior to insertion of arterial catheters. The purpose of this study was to determine if skin puncture or no skin puncture prior to insertion of an arterial catheter had any effect on catheter damage or ease of insertion.

\section{Methods}

Approval for the study was obtained from the hospital human research committee. The normal practice in our hospital was to make a skin puncture prior to insertion of arterial catheters. As we were assessing the result of omission of skin puncture, a separate consent was not considered necessary by the human research committee. In this prospective randomized study over a two month period in 1995, 110 patients undergoing elective surgery for intracranial tumour or cervical spine surgery requiring an arterial line for intraoperative monitoring were recruited. Sealed envelopes containing the group allocation (by random number table), as well as a plastic specimen bag for collection of removed arterial catheters were prepared.

Patients requiring an arterial line were identified on the operating list by the respiratory therapist (RT). Age, sex, weight, height, blood pressure were recorded for all patients. Other data including pulse quality (graded as weak, normal or bounding), insertion time, total number of passes, total number of catheters used and whether the patient was awake or anesthetised for catheter insertion were recorded for each patient by the RT and returned to the investigators. Prior to anesthesia induction, the RT opened the envelope containing group allocation in the operating room. The anesthesiologist was then asked to insert the arterial line with a skin puncture (SP) or no skin puncture (NP) as indicated. The decision to insert the arterial catheter with the patient awake or anesthetised was left to the discretion of the attending anesthesiologist. For patients with catheters inserted awake, lidocaine $2 \%$ local skin infiltration was performed. For patients with catheters inserted asleep, no skin infiltration was done. The catheter site was cleansed with povidoneiodine $10 \%$ solution and draped in the usual fashion. In the SP group skin puncture was performed over the arterial pulsation with an 18 gauge needle. In the NP group the arterial catheter was inserted directly without prior skin puncture. A 20 gauge, 1.25 inch Angiocath (Becton Dickinson Vascular Access, Sandy, Utah, U.S.A) was inserted into the artery. Timing of insertion began from the time of first skin entry and ended when the catheter was successfully threaded to the hub. If the catheter was withdrawn at any stage before re-advancement it constituted a 'pass'. The insertion technique (direct or transfixation) was at the discretion of the anesthetist and was also recorded. A plastic specimen bag with instructions for the neurosurgery ICU (NICU) staff accompanied the patient to the NICU after surgery. The catheters were later removed when clinically indicated and collected in the specimen bags provided. The catheters were examined microscopically under $\times 10$ magnification microscope for damage by an independent observer. The damage was classified as: 'frayed' (distorted, irregular edges and sharp tentacle like projections of the catheter tip including peeling away from stylet), 'shear'(a large tear in the catheter with or without fray), 'concertina'( catheter folding back on itself in an accordion like manner) and 'buckle' (sharp bend in the catheter). Ease of insertion was inferred from the number of attempts made, the number of catheters used, and the insertion time.

Between SP and NP groups, categoric data were analyzed using Chi-square analysis. Continuous data were expressed as mean \pm standard deviation and compared using Student's t tests. As the time of insertion, number of catheters and number of passes had a nongaussian distribution, Mann-Whitney $U$ test was used instead of Student's t test. A $P<0.05$ was considered statistically significant.

\section{Results}

Initially, 110 patients were recruited, 55 in each of SP and NP group. However, 28 catheters were misplaced or discarded before they could be examined and these cases were eliminated. A total of 82 patients completed the study, 36 in the SP group and 46 in the NP group (Table I). There were 38 men and 44 women. The number of patients with arterial catheters inserted awake or anesthetised are shown. There were no differences 
TABLE I Demographic data

\begin{tabular}{lll}
\hline & $S P$ & $N P$ \\
\hline No. of Patients & 36 & 46 \\
Age (yr) & $54 \pm 15$ & $53 \pm 14$ \\
Sex $(\mathrm{M} / \mathrm{F})^{*}$ & $16 / 20$ & $22 / 24$ \\
Height $(\mathrm{cm})$ & $168 \pm 10$ & $165 \pm 11$ \\
Weight $(\mathrm{kg})$ & $73 \pm 19$ & $73 \pm 15$ \\
Pulse quality & $24 / 10 / 2$ & $34 / 7 / 5$ \\
(N/W/B) $\dagger$ & & \\
Insertion & $21 / 15$ & $29 / 17$ \\
(Awake/ Anes $\ddagger)$ & & \\
\hline
\end{tabular}

$\mathrm{SP}=$ Skin puncture, $\mathrm{NP}=$ No skin puncture.

*M=Male, F=Female.

$\dagger \mathrm{N}=$ Normal, $W=$ Weak, $B=$ Bounding

$\ddagger=$ Anesthetized

TABLE II Catheter damage by microscopic examination

\begin{tabular}{lll}
\hline & $S P$ & $N P$ \\
\hline Frayed & 12 & 18 \\
Shear & 3 & 5 \\
Buckle & 1 & 0 \\
Concertina & 0 & 0 \\
Cathetcrs damaged $^{*}$ & 13 & 18 \\
\hline
\end{tabular}

*some catheters have more than one type of damage

TAB LE III Details of catheter insertion

\begin{tabular}{lll}
\hline & $S P$ & $N P$ \\
\hline No. of catheters & $1.7 \pm 1.4$ & $1.6 \pm 0.9$ \\
No. of passes & $2.0 \pm 1.7$ & $2.5 \pm 2.7$ \\
Insertion time (sec) mean & $180 \pm 325$ & $205 \pm 267$ \\
$\quad$ median & 62 & 77 \\
\hline
\end{tabular}

between the two groups in demographics, pulse quality or catheters inserted awake $v s$ anesthetised. Overall, the number of catheters damaged was $36.5 \%$ (31/82). The most common microscopic damage was "frayed" $(30 / 31,97 \%)$ while "buckle" and "concertina" were rare (Table II). Some catheters had more than one type of microscopic damage. There was no difference between the SP and NP groups in terms of catheter damaged $(13 / 36$ ps $18 / 46 ; P=0.78)$. The number of catheters, passes and insertion times are shown in Table III. The median times of insertion were $62 \mathrm{sec}$ for SP and $77 \mathrm{sec}$ for NP technique $(P=0.458)$. The number of catheters used and passes made were not different between the groups. There were no differences in the times required for insertion between staff or resident anesthesiologists $(P=0.719)$ and between awake or anesthetised patients $(P=0.973)$. However, the time required for direct insertion was shorter than that for transfixation (median of 42 vs $174 \mathrm{sec}, P=0.001$ ).

\section{Discussion}

Our results demonstrate that there are no advantages in making a skin puncture prior to arterial line insertion in terms of either catheter damage or time for insertion.

The technique of skin puncture prior to arterial line insertion is widely practised. Historically, when the first catheters were used to replace indwelling needles they were made of soft polyethylene. As the catheter was soft and loose fitting it was susceptible to being pinched by the skin resulting in catheter damage. ${ }^{10,11}$ A small skin puncture was made to prevent this pinching. With the advent of newer catheters this practice was abandoned for intravenous catheter insertion. However, it has persisted for arterial catheter insertion. The reasons cited in favour of this technique are lower incidence of catheter damage $e^{4,5,8,9}$ resulting in less vessel wall injury, prevention of stylet plugging with tissue ${ }^{6}$ and increased ability to discern vessel wall entry. However, there are disadvantages with this technique. It is wasteful and poses increased risk of inadvertent arterial wall puncture with a large bore needle while making skin puncture.

Dull $e t a l^{11}$ examined catheters for damage after insertion through the skin only, making no attempt to cannulate arteries or veins. They found no difference in the incidence of catheter damage between skin puncture and no puncture groups. Our study is the first in human subjects to determine if skin puncture prior to arterial catheter insertion is beneficial in terms of catheter damage or ease of insertion into the arteries. We found that there are no advantages in making a skin puncture prior to arterial line insertion in terms of either catheter damage or time for insertion.

Two methods of arterial cannulation practised are direct and transfixation. In the direct method only the anterior wall of the catheter is punctured but in the transfixation method both the anterior and posterior walls of the artery are deliberately punctured. Previous studies $^{12,13}$ have shown no difference with regard to ischemic complications between the two techniques and both the techniques are widely practised. In terms of time for insertion the direct method required less time for insertion in our study. However, as the direct and transfixation groups were determined posthoc we can only conclude an association and not causation.

There are several limitations to our study. Firstly, only one type and one size of arterial catheter in adult patients were used. Our results cannot, therefore, be extrapolated to other catheter types, sizes or pediatric patients. As smaller size catheters ( 22 or 24 gauge) are used in neonates and pediatric patients, we could not determine if skin puncture may be beneficial in that 
setting. Secondly, the conditions for insertion were not identical between SP and NP groups, as the choice to insert catheter awake or asleep was left to the discretion of attending anesthesiologist. However, when we analyzed the proportion of awake or anesthetized patients in both groups no difference was found. Time of insertion and catheter damage between cases performed awake or anesthetised were also similar. Thirdly, anesthesiologists accustomed to a particular technique (SP or NP) may be asked to employ another which could be more time consuming for them. As the common practice in our hospital was to perform a skin puncture prior to arterial catheter insertion, the SP group may have an advantage over the NP group. Fourthly, catheter damage could occur during insertion, while in situ or at time of removal. Therefore, presence or absence of skin puncture before catheter insertion is only one of the factors determining potential catheter damage. Fifthly, the small number of patients in the study could result in a type II error. A further study with a larger number of patients may result in lesser possibility of a type II error.

In summary, our results demonstrated no advantages in making a skin puncture prior to arterial catheter insertion in terms of catheter damage or time of insertion. This technique may be abandoned resulting in cost benefit and decreased risk of needlestick injury.

\section{Acknowledgment}

We would like to express our gratitude to all anesthesiologists and respiratory therapists for their help and assistance in our study.

\section{References}

1 Beards SC, Doedens L, Jackson A, Lipman J. A comparison of arterial lines and insertion techniques in critically ill patients. Anaesthesia 1994; 49: 968-73.

2 McEllistrem RF, O'Toole DP, Keane P. Post-cannulation radial artery aneurysm - a rare complication. Can J Anaesth 1990; 37: 907-9.

3 Talmage EA. Shearing hazard of intra-arterial teflon catheters. Anesth Analg 1976; 55: 597-8.

4 Gregory GA. Pediatric Anesthesia. New York: Churchill Livingston, 1988: 548.

5 Cook DR, Marcy JH. Neonatal Anesthesia. Pasadena, California: Appleton Davis, 1988: 156

6 Rogers MC. Textbook of Pediatric Intensive Care. Baltimore, Maryland: Williams and Wilkins, 1987: 1407.

7 Steward DJ. Manual of Pediatric Anesthesia. New York: Churchill Livingston, 1985: 62.

8 Grapenstein JS. Paulus DA. Clinical Monitoring Practice. Philadelphia: JB Lippincott, 1987: 77.
9 Stoelting RK, Miller RD. Basics of Anesthesia. New York: Churchill Livingston, 1989: 218.

10 Massa DJ. A plastic needle. Anesthesiology 1951; 12 772-3.

11 Dull $D L$, Forbes $R B$, Tinker $J H$. Efficacy of prior skin puncture in preventing iv catheter damage. Can J Anaesth 1991; 38: 213-6.

12 Jones RM, Hill $A B$, Nabrwold $M L$, Bolles RE. The effect of method of radial artery cannulation on postcannulation blood flow and thrombus formation. Anesthesiology $1981 ; 55: 76-8$.

13 Evans PJD, Kerr JH. Arterial occlusion after cannulation. BMJ 1975; 3: 197-9. 